\title{
FUTURE OF MICRO-GRIDS IN INDIA
}

\author{
Veena Kumari ${ }^{1}$ \\ ${ }^{I}$ Department of Electrical Engineering, Guru Nanak Dev Engineering College, India
}

\begin{abstract}
Micro-grid has advanced to a level of new dimension. Though the concept of Micro-grid is not that new because the premature electricity connections were certainly Micro-grids in the lead to inclusion to the local and the federal grids. Many significant tech-efforts have been devoted to the research of Micro-grids. This paper presents literature review on the already proven examples of importance of Distributed Energy Sources in the Grid Failure conditions. And what the future holds in the field of small-scale grids and how far the development and implementation can be foreseen of? This paper discusses both aspects reliability and cost of Micro-grid side by side.
\end{abstract}

Keywords: Micro-Grid, Energy Emergency, Distributed Generation, Reliability, Cost-Effective

\section{INTRODUCTION}

MICRO-GRID, as specified by the Federal Department of Energy, is a group of interconnected customer loads and distributed energy sources (DER) within clearly defined electrical boundaries that acts as a single controllable entity that can connect and disconnect from the grid (known as islanding) [1]. It can operate in Grid-mode or Island-mode. When a sudden blackout or urgency occurs, Micro-grids can be switched to Island-mode and in this way, critical loads need not to suffer[2-3].

In the event that India receives well over 5000 trillion $\mathrm{kWh}$ of pure solar energy each year, which is excessively more than that of electricity consumption of India. With this is mind, and looking at the geographical location of India, Microgrids must be considered and developed at the hand of solar cells and solar panels to overcome the frequent power failures and generate electricity [4].
Combined Heat and Power Technology has evolved in terms of multi-carrier energy hub to modern grid applications. According to "MicrogridKnowledge" by Siemens, the innovation of Distributed Energy Resources is widespreading side-lining the traditional utilities ensuring few outages or blackouts. Micro-grid is estimated to increase its roots by years to come. The most important aspect is the reliability and long term cost benefits because of which customers are bending towards this technology. The Microgrid cost depends mainly on the following factors[5]:

- Distributed generation assets

- Grid Automation

- Microgrid Optimization Software

- Development and Installation Costs

- Energy Storage

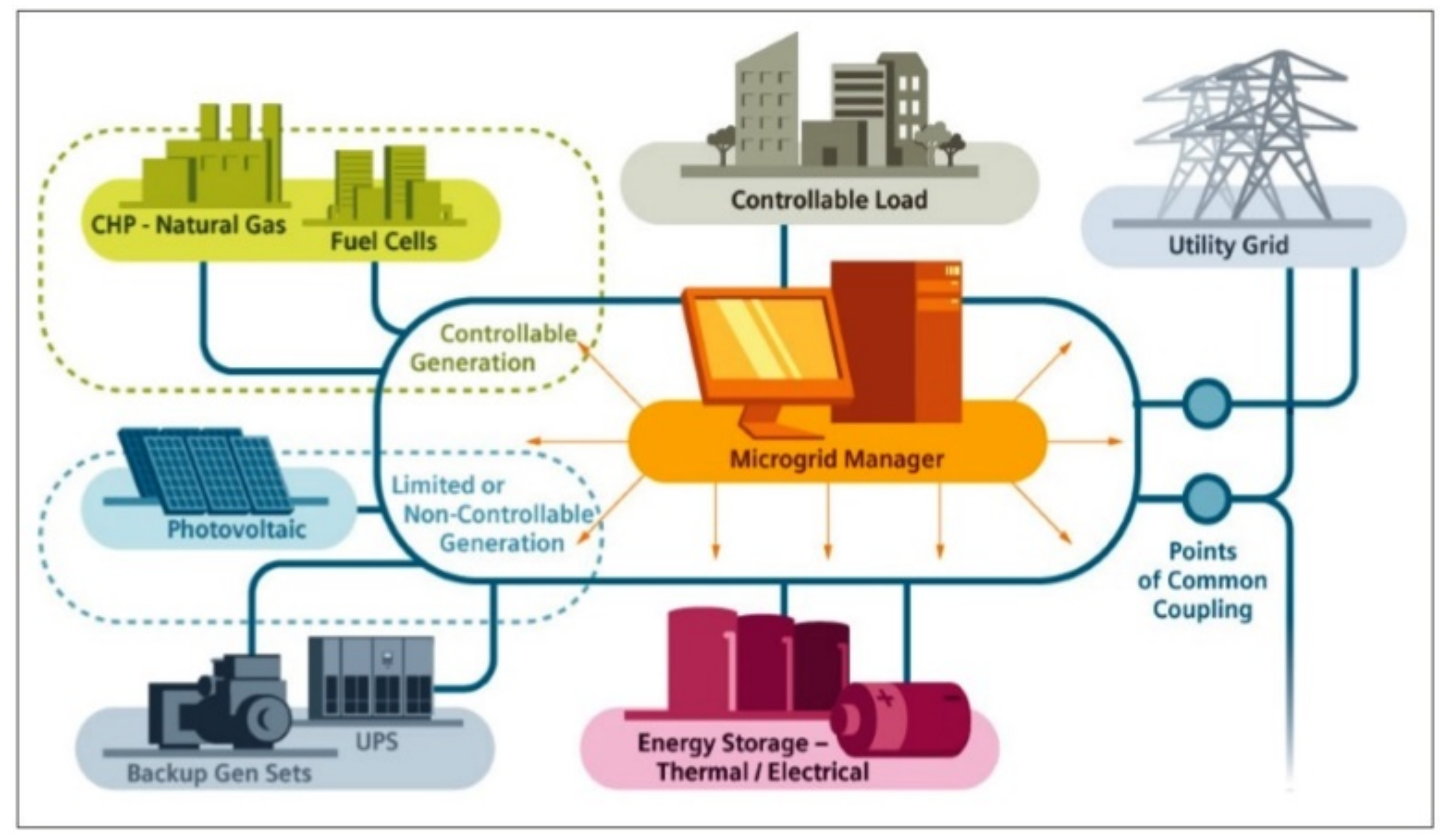

Fig 1: Microgrid Power Sources 


\section{CASE STUDIES}

\subsection{Micro-Grids - Future Cost-Cutter to Ever Increasing Power Rates}

According to San Francisco Chronicle, Santa Rita Jail in California established Micro-grid to cut the utility costs which will automatically switch in case of a blackout. The prisons need regular electricity to provide to the security cameras, recording systems, electronic door, perimeter fence alarms, heating and air conditioning systems [6].

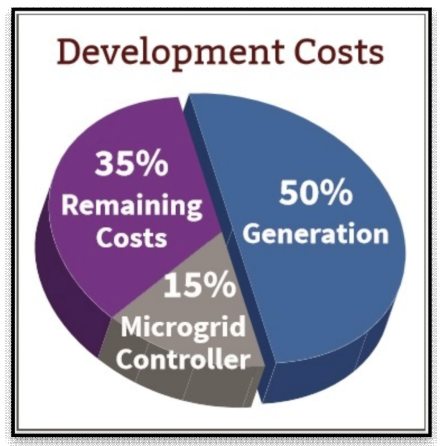

Fig 2

Microgrids are expected to explode into a $\$ 40$ billion-a-year global business by 2020 as reported by Navigant Research, a clean-technology data and consulting company. In United States, U.C. San Diego saves approximately $\$ 850,000$ a month by self-generating and using its own microgrid to fine-tune campus power consumption [7].

UC San Diego was awarded with 2010 Energy Star CHP Award by the U.S. Environmental Protection Agency in recognition of its high-efficiency, low-emission combined heat and power (CHP) plant that provides 85 percent of Campus Annual Electricity Needs[8].

\subsection{Reliability}

As reported by $\mathrm{ABB}$, it used flywheel-based energy storage in Microgrid to deliver power to Kodiak Island off the Alaskan Coast. Integrated Solar Diesel Microgrid is in process of installatiodewn at ABB's own premises in South Africa to magnify the use of Renewable Energy Resources and to ensure uninterrupted power supply even in the event of disconnection from Main Grid.[9].

Princeton University's Microgrid is a moral to all the regions of the world, when after facing a hurricane sandy which had put the whole New Jersey in darkness for days, shows the need of the hour for more researches and implementation in Microgrid. Here in the Princeton University, they have developed their on-campus power generation and delivery system which can provide 16-27 Megawatts in different seasons and emergency power-cut. [10].

Federal Drug Administration (FDA) White Oak Research Facility, Maryland. During SSS the local grid failed and the campus facility switched entirely over to its onsite natural gas turbines and engines to power all the FDA buildings on campus for two and a half days. (LaMonica 2012).New York University installed a natural gas-fired cogeneration facility in 2010 primarily to save money on energy and to reduce the University's carbon footprint with a side benefit of reliability. During SSS, NYU "islanded" itself and using its own cogeneration facility most of the University campus had power and heat.[12].

Microgrids is a great solution to the remote villages. One such is a Microgrid built by the Washington-based EarthSpark International which delivers power to 54 inhabitants of the village of Les Anglais. Likewise Africa, India and Latin America is embracing Local power grids that mix fossil-fuel generators with solar and wind power escorting cheaper and cleaner energy to the poor.

Adding further, A Microgrid was constructed by Northern Power Systems, a Barre, Vermount -based maker of wind turbines in Hawaii's big island in North Kohalafor peasants to help irrigate 400 acres of land [7].

\section{CONVENTIONAL VS MICRO-GRID}

1. Efficiency of conventional grid is low as compared to Microgrid.

2. Large amount of energy in the form of heat is wasted in conventional grid.

3. Power sources in Microgrid are small and are located in close proximity to load. [14]

\section{INDIA'S FIRST MICRO-GRID}

Village- Upari Babhan,Rajasthan

Co-ordinates: N26.58 205, E75.46221

Population:200-300

Generation $-15.78 \mathrm{~kW}$

Consumption - 10.43kW[14]

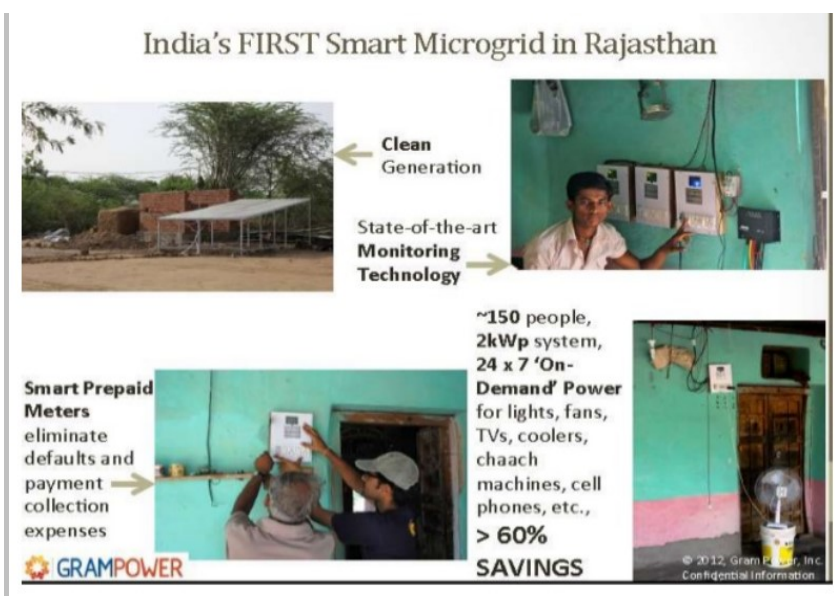

\section{FUTURE OF GRIDS}

Because of the factors affecting power generation, distribution and transmission, it is foreseen that Microgrids will be in use on a big scale by 2022 in various sectors as shown in Fig. 4. 
The microgrid application marked is assumed to mushroom by both growth and revenue by the end of 2022 (Fig, 5. and Fig. 6)[11]. In accordance with Zpryme \& IEEE study, the top three categories which would administer the Small scale grids the most are healthcare/Hospitals, Government (Military and Non-Military) and utilities (Fig. 7)[12].

As stated by Blog 'Readwrite.com', MIT's Technology Review recommends to focus on Microgrids for less disconnections and less destructrion with a decentralized system of networks and small vendors. India's target is to install 20,000 Megawatt of grid-connected solar power by 2022 [13].

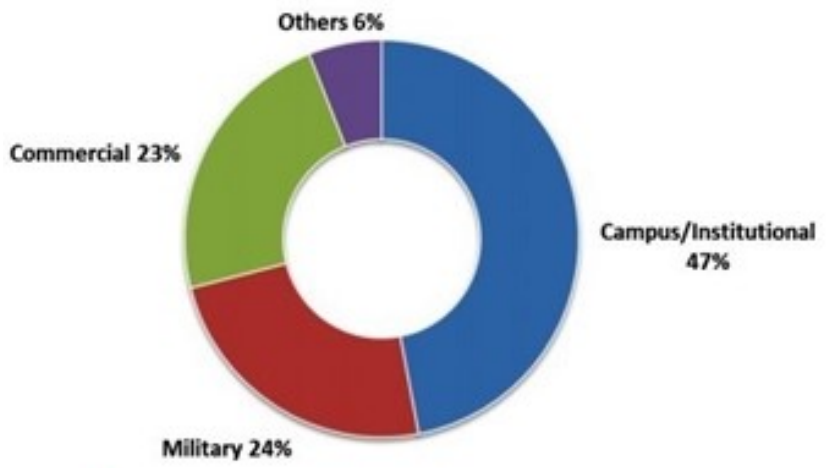

Fig.4. Forecasted microgrid application market in 2022

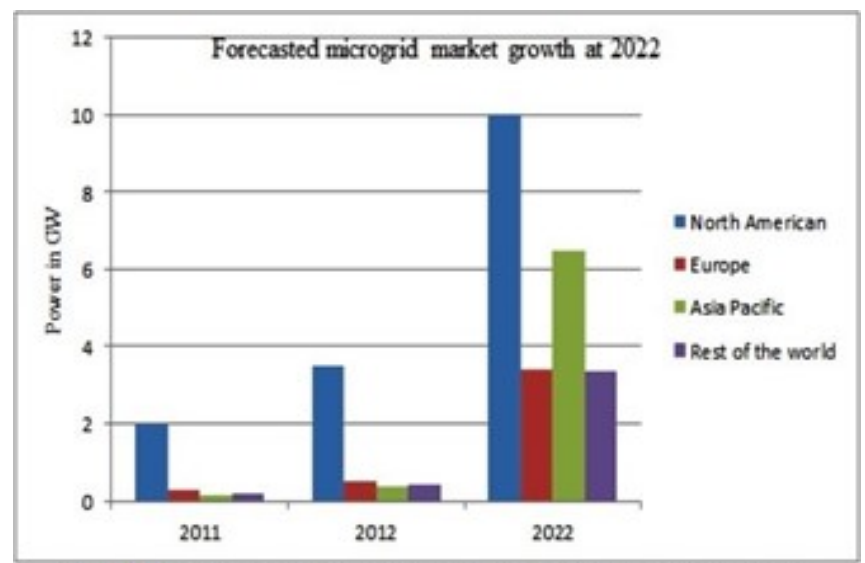

Fig. 5. Forecasted microgrid market growth in 2022

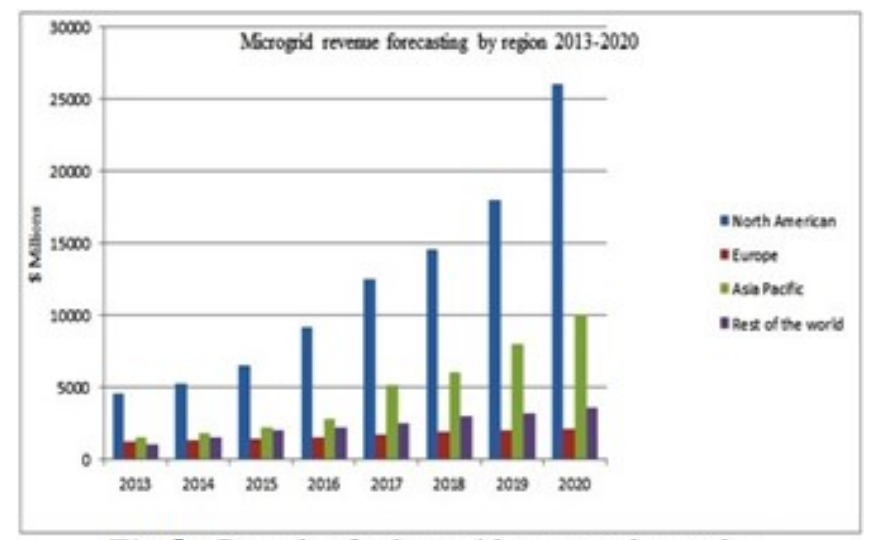

Fig.6. Growth of microgrid revenue by region

\section{Which Industries are most likely to deploy Microgrids over the next 5 years? (figure 22, source:zpryme \& IEEE)}

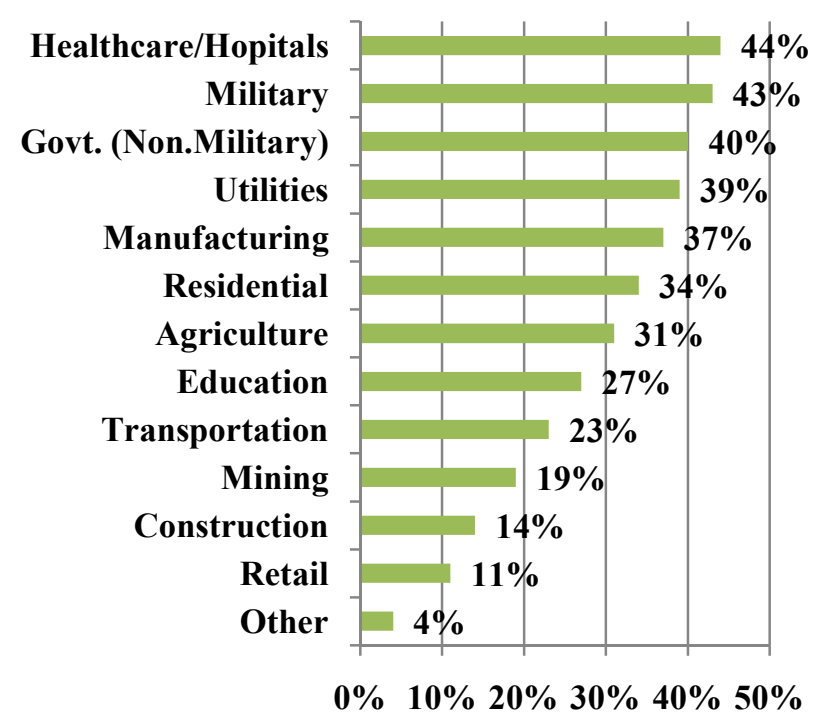

Fig 7. Zpryme/IEEE Study

\section{CONCLUSION}

Altogether, it is a necessity for human survival to innovate and develop new technology to keep going with nature while keeping in mind to reserve non-renewable resources. Microgrids are a wonderful gift by the engineers and researchers to lessen the fear of no electricity around and darkness. We cannot even imagine our life without energy. Specifically in hospitals, industries, research labs, and military, where disruption for even a single minute could be hazardous, Microgrids worklike a miracle. Besides, emission of Carbon Dioxide can be reduced and it ensures clean energy, security, resiliency and efficiency. Furthermore, use of renewable energy resources is a one-time investment with huge profits and it has the capability to turn the whole Power industry into a large business with local generation and transmission. The scope of Microgrids will see grand transitions in the grid-architecture.

\section{REFERENCES}

[1] http://www.techplanetjournal.org/2014/01/microgridsfuture-energy/

[2] Lubna Mariam, Malabika Basu, and Michael F. Conlon (2013, March), A Review of existing Microgrid Architectures, “Journal of Engineering"[Online], Volume 2013(2013), Article ID 937614, 8 pages.Available: https://www.hindawi.com/journals/je/2013/937614/

[3] E.Hossain et al; Mashroor Jawad; K.H. Rakibul Islam; Md Qays Akash (2016, July), Design a Novel Converter for Stability Analysis of Microgrid by Managing Controllable Load using Load Shaving and Load Shifting Techniques; and Optimizing Cost 
Analysis for Energy Storage System, "International Journal of Renewable Energy Research”, Vol. 6, No. 3, pp. $772-786$

[4] D.V.Avasthi, Gajendra Singh,(2014 August), Inspiring Young Engineers to Establish Stand-Alone Micro-Grid Enterprises for the Mitigation of Power Crisis and Unemployment in India, "International Journal of Science and Research (IJSR)", Volume 3 Issue 8, pp:1095-1099

[5] Siemens, "How Microgrids Can Achieve Maximum Return On Investment", "Microgrid Knowledge"http://sun-connectnews.org/fileadmin/DATEIEN/Dateien/New/5-

58418_MGKGuidetoHowMicrogridsAchieveROIpdf.pd $\mathrm{f}$

[6] Prison Legal News,

Source:

https://www.prisonlegalnews.org/news/2013/aug/15/ca lifornia-jail-installs-new-ampquotmicrogridampquotto-cut-energy-costs/

[7] Leonard Phillips, Big corporations embracing microgrids: A threat for utilities?, "International District Energy Association (IDEA)", IDEA Industry News

[8] UC San Diego News Center. Source: http://ucsdnews.ucsd.edu/archive/newsrel/general/1027SustainableOperations.asp

[9] Tilo Buehler, Ritwik Majumder, ABB Review (2016, March), Microgrid, pp: 38-40

Source:

https://library.e.abb.com/public/ef90d46c604d4790a2fe e3dc6af2d3f0/38-40\%203m6048_EN_72dpi.pdf

[10] https://www.princeton.edu/main/news/archive/S41/40/1 0C78/index.xml?section=featured

[11]Eklas Hossain, Ersan Kabalci, Ramazan Bayindir, Ronald Perez, A Comprehensive Study on Microgrid Technology,"International Journal of Renewable Energy Research",Vol. 4, No. 4, 2014, pp:1095-1107

[12] Ernest N. "Ernie"' Hayden, Securicon, LLC.Source: https://www.securicon.com/sites/default/files/Introduct ion $\% 20$ to $\% 20$ Microgrids $\% 20-\% 20$ Securicon $\% 20$ $\% 202013$ 1.pdf

[13] Microgrids and Solar Power, the Answer to India's Power, Source: http://readwrite.com/2012/08/09/microgrids-and-solarpower-the-answer-to-indias-power-crisis/

[14] Dr. Yajvender Pal Verma, MICROGRID: Architecture, Control and Operational Issues, Source: "National Seminar on Smart Grids and Alternative Sources of Energy- SGASE'16". 